\title{
Massive pulmonary embolism and thrombophilia
}

\author{
Iman Qureshi, Riwa Meshaka, Claire Donohue, Asad Ali
}

University Hospital Coventry and Warwickshire, Coventry, UK

\section{Correspondence to}

Dr. Iman Qureshi, Iman23@doctors.org.uk

\footnotetext{
To cite: Qureshi I, Meshaka R, Donohue C, et al. BMJ Case Reports Published online: [please include Day Month Year] doi:10.1136/bcr-2012008197
}

\begin{abstract}
SUMMARY
A 32-year-old man presented overnight to the accident and emergency unit with mild breathlessness on exertion. He was found to be hypoxic on room air and his chest $x$-ray revealed areas of patchy lung consolidation. He was given intravenous antibiotics for presumed community-acquired pneumonia. Unfortunately his condition deteriorated and he remained significantly hypoxic despite high-flow oxygen with ECG evidence of right heart strain. Further questioning revealed a history of protein $\mathrm{S}$ deficiency and a strong family history of venous thromboembolic disease. An urgent CT pulmonary angiogram showed an evidence of massive pulmonary embolism and the patient was successfully thrombolysed.
\end{abstract}

\section{BACKGROUND}

Pulmonary embolism is defined as a blockage of a pulmonary artery or one of its vessels by thrombus, fat, amniotic fluid or air. ${ }^{1}$ A massive pulmonary embolism is characterised by hypotension, shock, right ventricular dysfunction and/or myocardial injury. ${ }^{1}$

Venous thromboembolism in a young, healthy patient is uncommon in the absence of a provoking factor. Life-threatening pulmonary embolism, sufficient to warrant thrombolysis on admission in the context of thrombophilia remains a rare entity.

Protein S deficiency itself, contributes to $2 \%$ of all venous thromboembolisms presenting to accident and emergency. ${ }^{2}$ A Scottish study conducted in healthy blood donors showed prevalence of hereditary protein $\mathrm{S}$ deficiency ranging from $0.03 \%$ to $0.13 \% .^{3}$ Protein $S$ controls thrombin generation and fibrinolysis, ${ }^{3}{ }^{4}$ deficiency increases the risk of thrombotic events from a young age.

We present a case in which obtaining a thorough family history is paramount for establishing the diagnosis of a life-threatening condition such as massive pulmonary embolism. It highlights the importance of having a low threshold in the diagnosis of pulmonary embolism in young patients and requesting overnight emergency CT pulmonary angiograms.

\section{CASE PRESENTATION}

A 32-year-old man, having recently been diagnosed with a lower respiratory tract infection by his general practitioner, presented to the accident and emergency at $02: 00 \mathrm{~h}$ with worsening shortness of breath. He had experienced breathlessness on exertion with a dry cough for 2 weeks; however, his symptoms had worsened despite a course of oral antibiotics. The patient had no significant medical history, led an active lifestyle and was a non-smoker.

On admission to hospital, he was dyspnoeic at rest with no complaints of chest pain, haemoptysis or calf tenderness. On examination, the patient was tachypnoeic (respiratory rate, 32) and tachycardic (heart rate, 120), saturating at $78 \%$ on air with a stable blood pressure $(130 / 37 \mathrm{~mm} \mathrm{Hg})$. On auscultation of the lungs, bilateral coarse crackles were audible.

\section{INVESTIGATIONS}

The patient's blood results showed elevated white blood cells $\left(18 \times 10^{9} / \mathrm{l}\right)$, C reactive protein $(128 \mathrm{mg} /$ 1) and an arterial blood gas taken at room air showed an evidence of type 1 respiratory failure ( $\left.\mathrm{pH} 7.43, \mathrm{pO}_{2} 7.3 \mathrm{kPa}, \mathrm{pCO}_{2} 4 \mathrm{kPa}\right)$.

A portable chest $\mathrm{x}$-ray revealed patchy shadowing (figure 1) and ECG showed sinus tachycardia with right heart strain (figure 2).

Despite 15 litres oxygen, the patient remained breathless and hypoxic (oxygen saturations of $83 \%)$. On further questioning, he mentioned that his first cousin had suffered a pulmonary saddle embolism and had been diagnosed with protein $S$ deficiency. This had prompted other family members to have a thrombophilia screen and the patient had also been found to be protein $S$ deficient (figure 3).

An urgent CT pulmonary angiogram was requested at 04:30 h, which showed an evidence of extensive bilateral pulmonary emboli and right ventricular strain (figure 4).

\section{DIFFERENTIAL DIAGNOSIS}

Due to the degree of hypoxia, family history of thrombophilia and right heart strain, massive pulmonary embolism remained the most likely diagnosis.

Other differentials were also considered, such as the original diagnosis of community-acquired

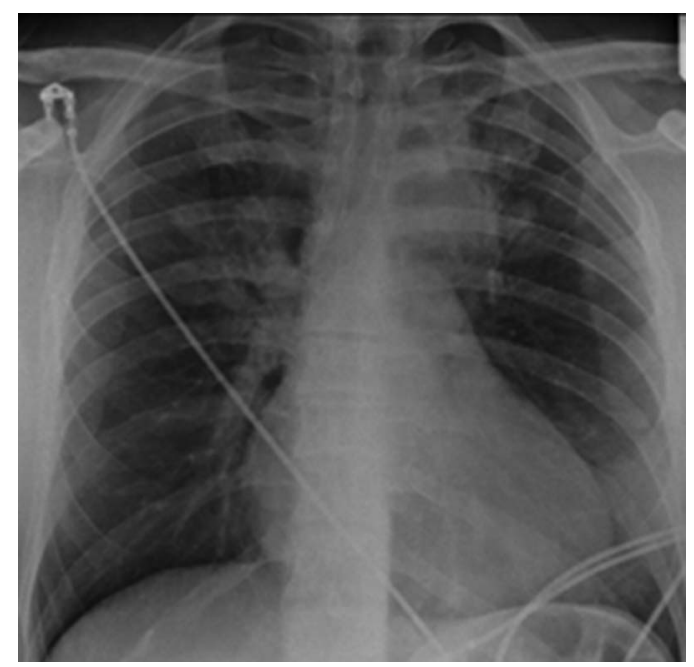

Figure 1 Posterior anterior chest x-ray showing dense consolidation in the left upper zone with patchy consolidation in the left lower and right upper zone. 


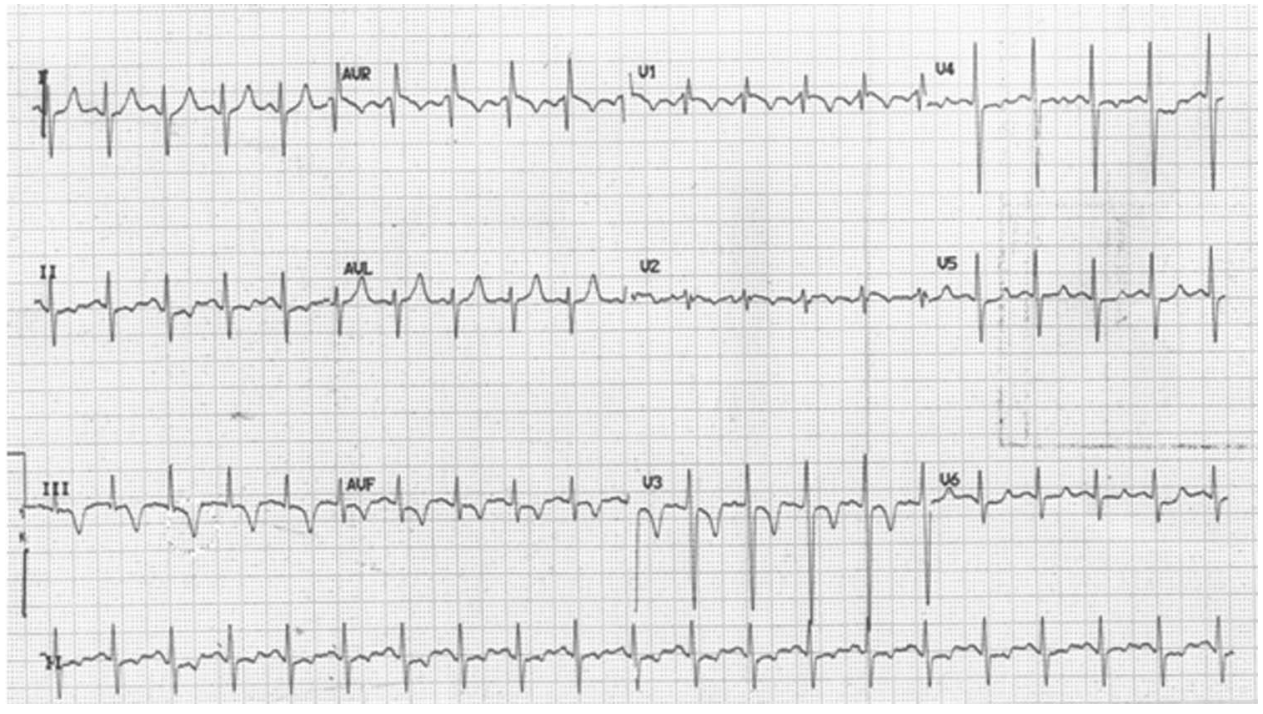

Figure 2 ECG showing sinus tachycardia with right axis deviation, right bundle branch block and deep T wave inversion in V1-V3.

pneumonia due to the patchy shadowing seen on the chest $\mathrm{x}$-ray. This did not explain the significant hypoxia despite highflow oxygen and the patient did not have fever or a productive cough.

A patient presenting with shortness of breath and low oxygen saturations raises the possibility of a pneumothorax, but clinical examination and chest $\mathrm{x}$-ray did not correlate with this diagnosis.

Importantly, cardiac causes such as an inherited cardiomyopathy or connective tissue disease causing acute valvular pathology or dissection should remain a high differential diagnosis. Although ECG showed right heart strain, the patient did not experience chest pain or syncope and had no phenotypical features of a connective tissue disorder on examination.

\section{TREATMENT}

Following the diagnosis of massive pulmonary embolism, the patient was thrombolysed at $04: 50 \mathrm{~h}$ with alteplase $(10 \mathrm{mg}$ given as an intravenous bolus, followed by an intravenous infusion of $90 \mathrm{mg}$ over $2 \mathrm{~h}$ ). He was moved to the intensive care unit for $24 \mathrm{~h}$ observation and his oxygen saturations improved almost instantly (figure 5).

He remained haemodynamically stable and was transferred to the respiratory ward. A repeated CT pulmonary angiogram showed almost complete resolution of emboli (figure 6).

\section{OUTCOME AND FOLLOW-UP}

The benefits of life-long warfarin greatly outweighed the risks for this patient, as the chance of thrombosis recurrence within a

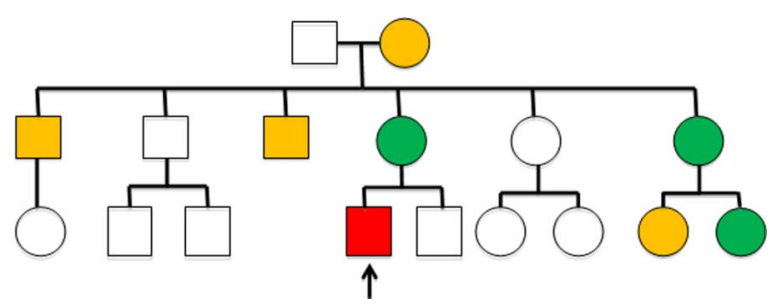

Figure 3 Family tree. Orange individuals have had a venous thromboembolism. Green individuals have been screened positive for protein $\mathrm{S}$ deficiency. Red indicates the patient in question. year is greater than $9 \% .{ }^{5}$ This was discussed with the patient, who agreed to begin warfarin therapy life-long. The side effects of warfarin and the need for regular blood tests were also discussed.

Any chronic condition that is life threatening may cause a significant amount of psychological stress. As the patient was ordinarily very active, it was made clear that exercise is still beneficial and should not be avoided due to anxieties over medication or disease recurrence. He has also been offered genetic counselling advice in the future, should he wish to start a family.

As a vegetarian, the patient was advised on the vitamin $\mathrm{K}$ content of certain foods. He was also warned about the risk of thrombosis in periods of immobility and advised to wear compression stockings during long-haul flights.

\section{DISCUSSION}

Unprovoked life-threatening pulmonary embolism is uncommon in healthy young patients. They can pose a diagnostic challenge, presenting in a non-specific and subtle way, masked by either the patient's level of fitness or lack of text-book symptoms. Therefore, it is important for clinicians to consider pulmonary embolism as a differential diagnosis for young patients and have a low threshold for requesting appropriate investigations.

Virchow's triad describes three primary causes of venous and arterial thrombosis: abnormalities in the circulating blood, stasis and injury to the vessel wall. ${ }^{6}$ Hereditary thrombophilias are associated with blood abnormalities and are characterised by venous thromboembolic events at a young age. These are often unprovoked and recurrent, occurring at unusual locations and associated with a family history. ${ }^{3}{ }^{6}$ Protein $\mathrm{S}$ deficiency predisposes to a 5-11.5 times higher lifetime risk of venous thromboembolism than the general population. ${ }^{3}$

Obtaining a thorough family history on admission can provide essential information to aid diagnosis. As this was the case with this patient, having a family history of thrombophilia prompted the admitting doctor to consider pulmonary embolism as a diagnosis. This resulted in requesting a CT pulmonary angiogram on admission, which revealed the life-threatening extent of pulmonary embolism, allowing immediate treatment.

The patient presented out of hours with significant hypoxia and right ventricular strain suspicious of massive pulmonary 
Figure 4 CT pulmonary angiogram on admission: (A) blue arrows showing bilateral upper lobe pulmonary segmental emboli; (B) blue arrows showing segmental emboli in the right and left lower lobe pulmonary artery branches. Red arrows showing consolidation in the left lung.

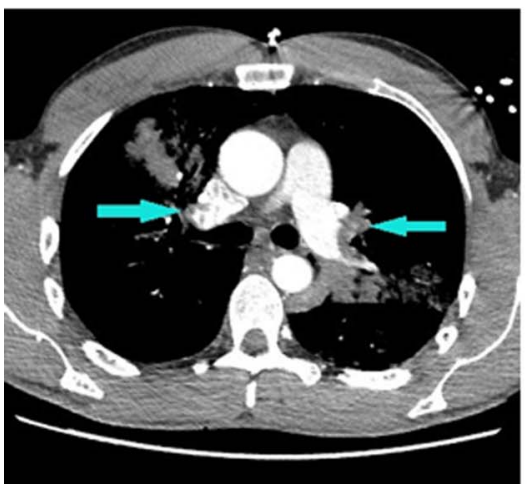

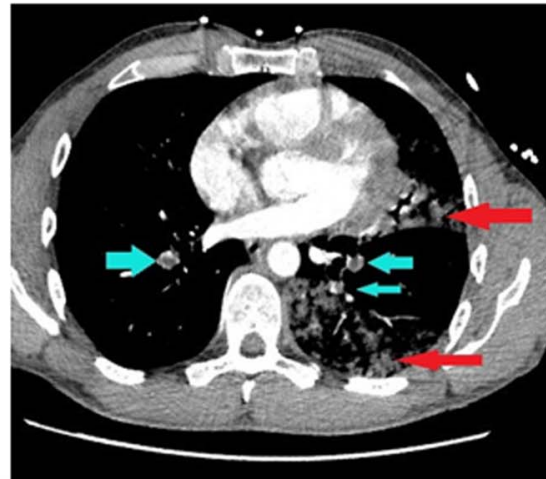

embolism, and an urgent CT pulmonary angiogram was the main investigative modality. ${ }^{7}$ Isotope lung scanning can be used in the diagnosis of pulmonary embolism, when the chest x-ray is normal and there is no significant cardiopulmonary disease. ${ }^{7}$ In patients with a coexisting clinical deep vein thrombosis, a leg ultrasound as the initial imaging test can be sufficient to confirm venous thromboembolism. ${ }^{7}$

Following the confirmation of massive pulmonary embolism, the patient received alteplase as he had no contraindications to thrombolysis. Patients not eligible for thrombolysis due to an increased bleeding risk may benefit from more invasive treatments such as catheter or surgical embolectomy in specialised centres. $^{78}$

There have been case reports of young patients admitted with venous thromboembolism in association with hereditary thrombophilia; however, a massive pulmonary embolism requiring thrombolysis remains uncommon. A report by Kam et al reported a case of a young patient with two episodes of pulmonary emboli, 11 years apart. A thrombophilia screen on the second admission, confirmed protein $S$ deficiency and the patient was successfully treated by emergency pulmonary embolectomy. ${ }^{9}$ A similar case has been reported in a paediatric patient requiring thrombolysis for a life-threatening pulmonary embolism in association with protein $\mathrm{S}$ deficiency. ${ }^{10} \mathrm{~A}$ case report by BayÕz et $a^{11}$ described a 38 -year-old woman requiring thrombolysis following diagnosis of a pulmonary embolism, discovered to have both activated protein $\mathrm{C}$ resistance and protein $\mathrm{S}$ deficiency. Wong et $a l^{12}$ outlined the case of a teenage boy

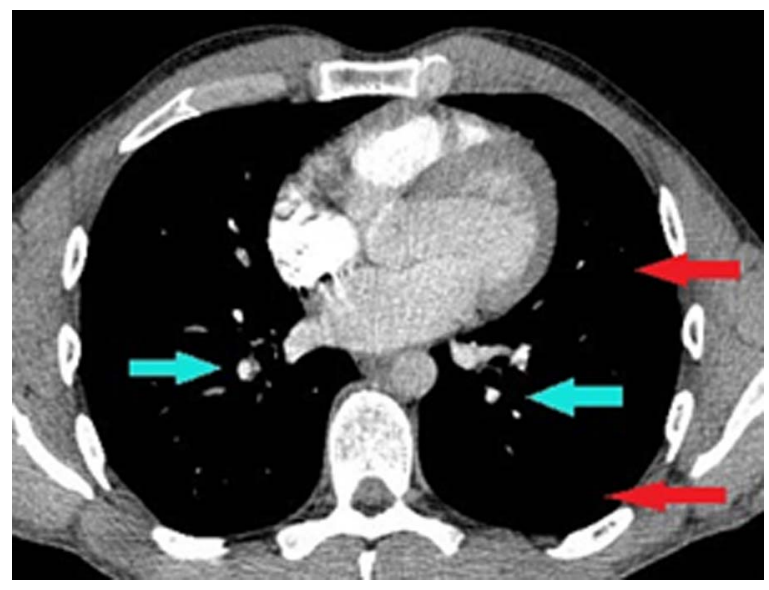

Figure 5 CT pulmonary angiogram post-thrombolysis blue arrows showing minimal residual emboli and red arrows showing resolution of consolidation.

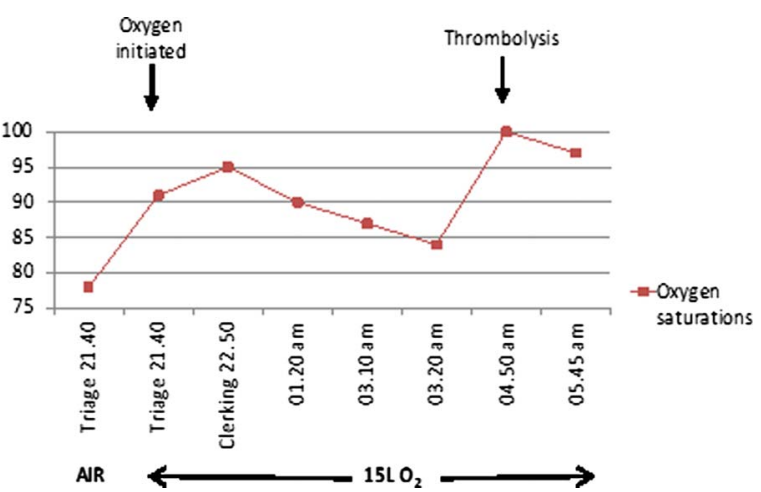

Figure 6 Oxygen saturations in accident and emergency with pre-thrombolysis and post-thrombolysis.

readmitted with collapse and cardiac arrest following an initial diagnosis of influenza B virus. Postmortem revealed massive pulmonary emboli and thrombophilia studies showed protein $\mathrm{C}$ and protein $\mathrm{S}$ deficiency.

\section{Learning points}

A thorough family history should be incorporated into the medical clerking of all patients admitted to the accident and emergency. Knowledge of the presence of hereditary illnesses, such as thrombophilia, provides invaluable guidance in creating differential diagnoses, prioritising investigations and providing the best care for the patient.

- Pulmonary emboli can present with non-specific symptoms. Meticulous clinical assessment of the patient as well as a low threshold for investigation on admission can be lifesaving.

- In young patients presenting with unprovoked pulmonary emboli, clinicians should consider inherited prothrombotic factors as a potential cause. ${ }^{8} \mathrm{~A}$ thrombophilia screen not only allows for better management of the patient, but also enables diagnosis of family members.

- In a hypoxic patient despite high-flow oxygen; think of pulmonary embolism, think of intensive care unit.

Competing interests None.

Patient consent Obtained.

Provenance and peer review Not commissioned; externally peer reviewed. 


\section{REFERENCES}

1 Torbicki A, Perrier A, Konstantinides $S$, et al. Guidelines on the diagnosis and management of pulmonary embolism. Eur Heart J 2008;29:2276-315.

2 Ten Kate MK, Van Der Meer J Protein S deficiency: a clinical perspective. Haemophilia 2008;14:1222-8.

3 Dykes AC, Walker ID, McMahon AD, et al. A study of protein $S$ antigen levels in 3788 healthy volunteers: influence of age, sex and hormone use, and estimate for prevalence of deficiency state. Br J Haematol 2001;113:636-4.

4 Biguzzi E, Razzari C, Lane DA, et al. Protein S Italian Team (PROSIT). Molecular diversity and thrombotic risk in protein S deficiency: The PROSIT Study. Hum Mutat 2005;25:259-69.

5 Kearon C, Kahn SR, Agnelli G, et al. Antithrombotic therapy for venous thromboembolic disease: American College of Chest Physicians Evidence-Based Clinical Practice Guidelines (8th edition). Chest 2008;133(6 Suppl):454S-545S.

6 Khan S, Dickerman JD. Hereditary thrombophilia. Thromb J 2006;4:15.
7 British Thoracic Society Standards of Care Committee Pulmonary Embolism Guideline Development Group. British Thoracic Society guidelines for the management of suspected acute pulmonary embolism. Thorax 2003;58: 470-84

8 Kucher N. Catheter embolectomy for acute pulmonary embolism. Chest 2007; 132:657-63.e

9 Kam RM, Tan AT, Chee TS, et al. Massive acute pulmonary embolism in protein S deficiency — a case report. Ann Acad Med Singap 1994;23:396-9.

10 Degan TA. Thrombolysis in pulmonary embolism: an adolescent with protein $S$ deficiency. J Am Board Fam Prac 1994;7:523-5.

11 BayÕz H, YÕlmaz L, Baúay N, et al. Massive pulmonary thromboembolism due to activated protein $\mathrm{C}$ resistance and protein $\mathrm{S}$ deficiency. Turk Respir J 2006;7:128-30.

12 Wong A, Malhotra A, Woo WWK, et al. Fatal pulmonary embolism in a teenager: case report. Hong Kong J.Emerg.Med 2006;13:100-4.

Copyright 2013 BMJ Publishing Group. All rights reserved. For permission to reuse any of this content visit

http://group.bmj.com/group/rights-licensing/permissions.

BMJ Case Report Fellows may re-use this article for personal use and teaching without any further permission.

Become a Fellow of BMJ Case Reports today and you can:

- Submit as many cases as you like

- Enjoy fast sympathetic peer review and rapid publication of accepted articles

- Access all the published articles

- Re-use any of the published material for personal use and teaching without further permission

For information on Institutional Fellowships contact consortiasales@bmjgroup.com

Visit casereports.bmj.com for more articles like this and to become a Fellow 